ULRIKE BURRMANN

University of Dortmund, Germany

ENRICO MICHELINI \#

University of Dortmund, Germany
TORSTEN SCHLESINGER

Ruhr University Bochum, Germany

JACQUELINE TUCHEL

Chemnitz University of Technology, Germany

TINA NOBIS

Humboldt University of Berlin, Germany

\title{
SPORT OFFERS FOR REFUGEES IN GERMANY PROMOTING AND HINDERING CONDITIONS IN VOLUNTARY SPORT CLUBS
}

\begin{abstract}
After the long summer of migration, strong social and political movements of solidarity with and resistance against refugees developed in Europe. Expressions of solidarity and resistance were also recognisable in the sport system, especially in voluntary sport clubs (VSCs). As a result of this observation, the following article addresses the question: "Which organisational conditions of VSCs promote or hinder the implementation of sport activities for refugees?" To this aim, the article analyses and discusses the results of three research projects concerning sport offers for refugees in Germany. The interview material $(n=49)$ collected in these projects was examined through the qualitative technique of thematic analysis and interpreted through a systems theoretical framework. The results show that conditions that promote and hinder the implementation of sport offers for refugees were identified in all formal (decision programmes, communication channels, and human resources) and informal (organisation culture) decision premises. Furthermore, the implementation of sport offers for refugees is particularly dependent on human resources within the sport clubs. The data shows that the resolute will of individuals or small groups of people is highly relevant for the implementation of these sport offers. Finally, when it comes to organizing support for refugees, VSCs display an unexpected dynamic and a high capacity to mobilise resources within a short period of time. The discussion reflects these results and articulates strategies to safeguard, foster, and facilitate the social engagement of VSCs in relation to refugees.
\end{abstract}

Keywords: Refugee; migration; participation; sport; Voluntary Sport Club; volunteer.

\footnotetext{
\# Corresponding author: University of Dortmund, Germany, Institute of Sport and Sport Science, Otto-Hahn-Str. 3, 44227 Dortmund. E-mail: enrico.michelini@tu-dortmund.de
} 


\section{Introduction}

Particularly since the "long summer of migration" in 2015, Germany has faced on-going, controversial debates about the social integration of refugees, which also refer to the role of sport. Sport settings are often seen as motors of integration (European Commission 2007, German Federal Government 2007, Rittner and Breuer 2004) that promote social, cognitive, and language competences (Mutz 2012, Nobis 2013, Rittner and Breuer 2004). Particularly voluntary sport clubs (VSCs) are seen as organisations that play a crucial role in promoting the social integration of specific target groups (Block and Gibbs 2017). We understand VSCs as non-profit-organisations which are not founded on remuneration or obligation (Horch 1989:203). They can instead be defined as communities of interest which produce and provide sport offers to its members, while relying on the principles of democratic organisation, volunteering, voluntary membership, and autonomy (Horch 1989:204). Yet, VSCs' potential as motors of integration can only be realized if refugees are actually given access to sport clubs. Moreover, the integration of refugees is not a self-evident goal of VSCs, it rather depends on concrete efforts, capacities, and the willingness of VSCs to realise this aim. Against this background and in close reference to Luhmann's systems theory, we address the question: "Which organisational conditions of VSCs promote or hinder the implementation of sport activities for refugees?"

We will explore this question by using recent studies concerning sport and integration in Germany (Burrmann, Rübner, Braun et al. 2014, Burrmann, Mutz and Zender 2015, DOSB 2014, Kleindienst-Cachay, Cachay, Bahlke et al. 2012, Seiberth 2012) and in other European countries (Elling, Knoppers and De Knop 2001, Lidor, Schneider and Koenen 2011). These studies have generated the following relevant knowledge: sport is not per se an instrument of social integration; migrants are a heterogeneous group; migrants are generally underrepresented in sport clubs, with the exception of male youths; migrants are relatively overrepresented in some and underrepresented in other sport disciplines. The research programme mentioned above suggests that the following conditions for setting up sport activities for migrants are necessary: a corresponding sensitivity and qualifications of VSC-members to constructively deal with diversity; a respective specification of goals and criteria for success to foster the openness of sport clubs; the representation of migrants in VSC positions and posts to promote integration.

However, it is important to note that refugees are a sub-group within the community of migrants that are demarcated by specific characteristics (Castles 2003). According to the United Nations High Commissioner for Refugees (UNHCR 2010), a refugee is a person who, owing to well-founded fear of being persecuted for reasons of race, religion, nationality, membership of a particular social group or political opinion, is outside the country of his nationality and is unable or, owing to such fear, is unwilling to avail himself of the protection of that country. (p. 14) 
The differences between migrants and refugees are not only limited to the (mostly involuntary) nature of their migration. Forced migration is often accompanied by traumatic experiences of war, loss of or separation from family members, dangerous journeys to a country of asylum, prolonged periods in refugee camps, and uncertain prospects of permanent residence (Binder and Tošić 2005, Ha and Lyras 2013, Hartley, Fleay and Tye 2017). These experiences can strongly influence the emotional well-being of refugees, and also result in less physical activity. Recent systematic literature reviews (Caperchione, Kolt and Mummery 2009, O’Driscoll, Banting, Borkoles et al. 2014) have in fact concluded that everyday issues (employment, income, access to medical services, housing, and education) are likely to precede sport and physical activities in terms of priority after resettlement; that refugees were more physically active in their home country than in their host country; and that escape-related post-traumatic stress is associated with less physical activity.

Moreover, previous empirical findings and practical expertise of VSCs in the field of sport and integration should not be transferred too hastily and naively when working with and conducting research on refugees. Therefore, the request for further research carried out in this field is current and urgent.

The last few years have thus offered a unique opportunity to social scientists seeking empirical information about the response of the sport system to societal change and its challenges. The so-called "European Refugee Crisis" (Clayton 2015) offered a chance to investigate how sport clubs have (or have not) managed to implement sport offers for newly arrived migrants and how they have (or have not) managed to provide support. Three research groups simultaneously used this opportunity and explored sport offers for refugees in Germany. This article merges, analyses, and discusses the data generated in these projects. In order to identify conditions which promote and hinder the creation of sport offers for refugees, we use a theoretical background based on systems theory (Luhmann 2003) that is tailored for examining (sport) organisations.

\section{Theoretical Framework}

Luhmann's systems theory assumes that communication-based function systems have differentiated in modern society. One of the specific mechanisms for stabilising expectations of function systems are formal organisations, which can fulfil the goals of function systems through their specific operations (Schimank 1988). According to Luhmann (2006), organisations must be viewed as autopoietic social systems consisting of and reproduced through (communicated) decisions. Thus, all observable organisational features, such as aims, hierarchy, or integrative attitudes for specific population groups, are results of preceding organisational decisions. The following decision premises are classically distinguishable in organisations' structures (Luhmann 2006, Thiel and Mayer 2009):

1) Decision programmes define the purposes of the organisation and how these can be achieved. Decision programmes are traditionally differentiated between 
purpose programmes, which distinguish and specify goals, and conditional programmes, which determine how to react under certain circumstances.

2) Communication channels represent horizontally- and vertically-differentiated networks, which specify distributions of tasks, hierarchies or work processes. In VSCs, central tasks are normally linked to honorary posts and there is considerable ambiguity concerning the responsibility for specific tasks.

3) Human resources are concerned with assigning persons to different fields of action and responsibility by identifying and matching their qualifications. Staff recruiting plays a crucial role, because different persons are likely to make different decisions within the same field of action.

4) Organisational culture involves decision premises that are not explicitly formulated but are nevertheless accepted by club members. Organisational culture develops through VSC's traditions, histories, routines, and informal norms.

The sport system is a function system, which organises its operations through the exclusive logic of "victory/defeat" (Bette 1999, Stichweh 1990), and VSCs are its representative organisation form. However, as organisations are also designated places for structural couplings between systems (Luhmann 2002a: 396401), VSCs do not only follow the logic "victory/defeat", but may also pursue goals such as the promotion of health, education, and social inclusion. Integration processes are fundamentally supported in VSCs by the opportunity to participate in the clubs' communication processes (Meier, Riedl and Kukuk 2016). While the exclusion of specific population segments is not (usually) foreseen by VSCs, decision premises may nonetheless hinder integration processes (Seiberth, Weigelt-Schlesinger and Schlesinger 2013).

Against the perspective of systems theory, VSCs have been analysed in terms of organisation-sociological aspects (Heinemann and Horch 1988, Horch 1989, Thiel 1997, Thiel and Meier 2004, Thiel and Meier 2008, Thiel and Mayer 2009) and also in respect to the integration of migrants (Bahlke and Kleindienst-Cachay 2017, Kleindienst-Cachay et al. 2012, Meier et al. 2016, Seiberth et al. 2013). However, this research programme did not focus on refugees as a sub-group, until now. Building on these studies and the state of art of international research, this article addresses this gap by focussing on conditions that promote and/or hinder VSCs in creating sport offers for refugees in Germany.

Recent findings about sport clubs in Germany have shown that $18.2 \%$ of German sport clubs organise offers for refugees (Breuer, Feiler and Nowy 2017:69). Since our data material only concerns VSCs, which provide sport offers to refugees, the article illustrates how sport clubs have successfully opened their doors to refugees, while it does not address how and why others keep their doors closed. 


\section{Methodology}

This article merged the empirical material of three research projects: as part of each project, semi-structured qualitative interviews ${ }^{2}$ with people directly or indirectly responsible for sports activities for refugees in VSCs were conducted. These 30 to 90 -minute interviews $(n=49)$ share plenty of common topics and often entail long narrations. They were re-examined for this article by using thematic analysis (TA) and interpreted through the system theoretical framework. The three projects are briefly presented below.

1. The scientific evaluation of "Orientation through Sport" (OtS): OtS is a programme financed by the German Federal Government and carried out by the youth section of the German Olympic Sports Confederation. The programme aims to financially support the establishment of sport offers for young, unaccompanied refugees. Both sport federations and sport clubs carried out these offers nationwide. A research team of the Technical University of Dortmund and the University of Munster evaluated OtS in 2017. In this article, the analysed empirical material concerning $\mathrm{OtS}$ comprises 25 telephone interviews conducted with persons responsible for sport offers across Germany.

2. Sport for and with Refugees ( $\mathrm{SfwR}$ ): This research project was carried out by the Technical University of Chemnitz and aimed inter alia at describing the actual state of sport-related refugee work in the city of Chemnitz (Saxony) by focussing on the potential, deficits, and best practices of sport offers in local VSCs. The analysed material of the SfwR project encompasses 10 semi-structured interviews conducted with persons responsible for the sport offers.

3. Refugee Work of Sport Clubs (RWoSC): This project was part of a lager research cluster about flight and solidarity carried out by Humboldt University of Berlin. It analysed motives, practises, and challenges of sport clubs that focus on the integration of refugees in Berlin and in Saxony. The analysed material of this project includes 14 interviews with board members and coaches responsible for the sport offers.

In order to process this material, the interview catalogues were aggregated and analysed as a whole data set. ${ }^{3}$ This article uses TA as a method for qualitative data analysis. TA is "a method for systematically identifying, organizing, and offering insight into patterns of meaning (themes) across a data set." (Braun and Clarke 2012:57) It enables the identification of commonalities within the topics that were discussed in the interviews and makes sense of them. Among all existent patterns across the data set, the analysis sought to identify those points relevant to evaluating the research question: "Which organisational conditions of VSCs promote or hinder the implementation of sport activities for refugees?"

These further methodological choices characterise in which ways TA was used for the analysis of the data: inductive and deductive approaches were com-

${ }^{2}$ These projects also employed additional empirical methods (document analysis, participative observation, and questionnaires) and had different research questions.

${ }^{3}$ As some of the VSCs expressed the wish to remain anonymous, direct quotations from the interview catalogue were assigned with the project acronym, followed by the interview number and the lines numbers of the respective transcript. 
bined $^{4}$; a descriptive sociological orientation was chosen; and a constructionist epistemological position based on Luhmann's systems theory was applied. These choices are functional for inquiries of the topic at hand, are in line with the sociological aim of the article and allow exploring the perspective of the persons responsible for the sport offers. With this in mind, all interview material was examined systematically to answer the research question.

Following the methodological guidelines of Braun and Clarke (2006), the interviews were analysed in five phases: (1) familiarisation with the material; (2) generation and grouping of provisional codes; (3) collation of the codes into broader themes; (4) review of themes and the removal of overlaps and of untreatable topics; (5) definition and naming of themes. This final stage was carried out together with other authors of this article by crosschecking, disambiguating and clarifying the themes and respective coding.

\section{Results and Discussion}

The results show that the provision and implementation of sport offers to refugees imply evident changes in routine operations of VSCs. Many projects for refugees were developed on short notice in order to provide immediate help and first solutions. Moreover, most refugees cannot easily access classical sport offers, and formal openness towards such a target group does not suffice to ensure their integration in sport. ${ }^{5}$ As observed by Breuer at al. (2017), VSCs must change their traditional recruiting and bonding strategies in order to reach refugees.

Concerning the recruiting strategy, the need for active promotion of offers at reception centres, refugee camps, or in other places where refugees live is crucial. Furthermore, collaboration with third parties, like the Red Cross, social workers, refugee camp staff, other sport clubs, or the municipality, is considered relevant and sometimes even crucial for its success.

Contact partner (CP): We immediately, when refugees came to [location], we immediately went there and made offers. "Guys, you can do sports with us". Children from the whole region, around 14 , there was a soccer group, boys and girls mixed, it was amazing. Then, unfortunately, the gym, where the sport offers took place, was taken from us. We continued the sport offers, but not for this group, which disbanded. But we have fitness groups in a running group. We tried to do as much sport with refugees as possible, but it wasn't easy to reach the refugees, that's the big problem, because for the operators, it's only a $8-4$ job. (RWoSC-7: Lines 31 )

\footnotetext{
${ }^{4}$ The main categories were created deductively (or rather, theory-guided), but the deep examination of the material implied a fluctuation between deductive and inductive analysis and the development of inductive sub-categories from the material.

${ }^{5}$ A thought-terminating cliché of sport clubs is that refugees are welcome and that they can certainly join the club if they want to, but do not undertake actions to facilitate their inclusion.
} 
In many cases, sport offers were especially introduced for refugees, or existing offers were adapted to meet the refugees' specific needs ${ }^{6}$. Occasionally, the VSCs carried out the offers at reception centres or refugee camps. The schedule for these offers was flexible and was sometimes modified radically, in order to meet the needs of the refugees.

I: How many refugees are involved in your club?

$\mathrm{CP}$ : Overall, we have 80 refugees in the OtS program. (...) We make offers for them in different areas. So not only in the rowing courses, but also swimming courses, running, bike-riding, and indoor sports. (OtS-15: Lines 7-8)

Concerning bonding strategies, when possible, the VSCs offered additional services for refugees, like transportation to the facilities and back, help with school assignments, language teaching, or childcare ${ }^{7}$ during the sport offers. The interviews show that minor misbehaviours (for example, concerning the punctuality and the reliability in participation) were tolerated, which is rather unusual for VSCs. In many cases, the activities were provided free of charge. ${ }^{8}$

I: What did it look like regarding compulsory insurance or membership fees?

CP: They didn't pay any money. For the refugees, it was free. And there were offers for the refugees to do some sort of an apprenticeship to train others. (OtS-18: Lines 51-52)

In order to further analyse how VSCs set up activities for refugees and mobilise these resources, a closer look at their decision premises will now be undertaken.

\section{Decision Programmes}

Usually, decision programmes of VSCs contain neither restrictions nor the goal to reach specific population groups. (Seiberth et al. 2013:180) VSCs are thus formally inclusive, but may limit the participation of certain groups, such as refugees, in other ways. Indeed, the integration of refugees into VSCs implies introducing sports offers which allow people with (and without) a refugee background to take part in activities independently of their cultural identities.

Concerning purpose programmes, all the sport clubs analysed in this article implemented sport offers for refugees, while most of their official statutes did not entail this goal. Theoretically, such practices should also imply a change in a clubs' purpose programme. However, only a few interviewees indicated that the goals of the organisation had been redefined in the VSC statute or charter.

\footnotetext{
${ }^{6}$ Breuer et al. (2017:47) report that 11.3\% of VSCs in Germany created such specific activities.

7 The narrations of the interviews only rarely concern female participants. Since their marginality in the sport offers was not further questioned, this aspect will not be further discussed in this article.

${ }^{8} 10.2 \%$ of all VSCs in Germany conduct activities for refugees for free or at a discounted price. (Breuer et al. 2017:47)
} 
$\mathrm{CP}$ : For example, this means that we now do an international workshop against discrimination etc. on the training trip. This is a big concern for us and has been explicitly changed in the statute, so it's unambiguous that we try to create a safe space, well it's more a sort of utopia or a discussion, or we are rather eager to do something against it, when it comes to discrimination. (RWoSC-1: Line 25)

According to our theoretical assumptions, conditional programmes concern themselves with how organisational purposes should be achieved by predetermining how decisions are made under certain conditions. (Luhmann 2006) Most VSCs do not have guidelines and measurable objectives for integration policies, which makes it hard to determine whether and how these decision programmes contribute to the goal of supplying sport offers for refugees. In VSCs, these uncertainties are compensated by personalising conditional programmes. (Thiel and Meier 2004:112, Thiel and Mayer 2009:88) The main parameter of orientation is the opinion of decision makers within the club, normally the chair or experienced club members. The personalisation of decisions will be further discussed in the section on human resources.

Finally, our data suggests that the implementation of sport offers for refugees follows certain "historical" pathways. The existence of previous integration programmes and offers for other population groups (in particular for migrants, but also for disadvantaged and disabled people) are sometimes mentioned in interviews as a facilitating factor in the creation of sport offers for refugees.

I: May I ask why you took the initiative - the club in general - to participate in the „Orientation through Sport” programme?

$\mathrm{CP}$ : Yes, this is linked to our orientation. Because (...) we are a very new club and (...) our motto is "rowing for everybody". And it was clear from the beginning that we want to open the rowing sport for all sections of the population that were principally excluded. For this reason, we have a post for inclusion so that exactly this group of disadvantaged people - so people with physical, mental and social needs - can be introduced to rowing sport. And (...) this was the idea and then it involved the realisation, in which we already well prepared through para-rowing, with disabled athletes. And through (...) the refugee wave in 2015 , which was so to speak just before its climax, or at its climax, in July 2015 - this was the idea at hand! (OtS-15: Lines 9-11)

In conclusion, the implementation of sport offers for refugees implies a change in the decision programmes of VSCs. However, this change can rather be understood as a consequence of the VSCs' practises than as a condition for initiating processes of change within the organisation. Indeed, the previous implementation of integrative offers seems to be a good predictor of the integrative 
capacity of a club. The presence or addition of "integration" as an explicit goal of VSCs may lead to a virtuous process of specification and concretisation of this goal (Thiel and Mayer 2009). Nevertheless, other decision premises may be more decisive for explaining the implementation of sport offers for refugees.

\section{Communication Channels}

Positions and hierarchies influence how and which goals will be followed within an organisation. We examined those communication channels in VSCs, which can (positively or negatively) influence the achievement of integrative goals, like the chair, the general assembly, specific posts for integration, and information oligarchies.

While the chair of a VSC plays an important role in the initiatives of the club, the decision to carry out offers for refugees was only rarely made by the individual occupying this post alone:

I: Who was the major initiator in your club?

CP: We, the board, we were... we made the decision and got the coaches. Of course, there were issues like "can I do this?" (RWoSC-7: Lines 49-50)

VSCs in Germany are managed through a quasi-bottom-up principle. (Seiberth et al. 2013:185, Thiel and Mayer 2009:91) $)^{9}$ Relevant decisions need to be negotiated and discussed in the general assembly, which has veto power over decisions of the chair. However, the interviewees only rarely mentioned negotiating on this topic at the general assembly and did not mention power struggles to push the decision of carrying out sport offers for refugees.

I: So once a year, there is an annual general meeting in the sport club. And the activities are presented. And that was very positive. So the members considered it to be very purposeful, excellent, helpful that there simply was an attempt to integrate the boys into the village's community. (OtS-9: Lines 194)

Seiberth et al. (2012:208, 2013:184) observe that a sport clubs' integration potential also depends on the extent to which clubs create (mostly honorary) positions within the organisation that explicitly deal with the topic of integration, in this case the integration of refugees. However, the interviews only rarely attribute the decision to create sport offers for refugees to such a post and make no mention of creating such a post; VSCs, which already had these posts, did not need to potentiate them.

Instead the data suggests that such a decision was mostly made by individuals or small groups of people who were members of the club and include both low

\footnotetext{
${ }^{9}$ Top-down decisions made by leading positions that are compulsory for all members are not characteristic of sports clubs.
} 
(trainers) and high (chair) hierarchical positions. Notably, VSCs' communication channels are influenced by so-called information oligarchies (Schimank:14, Thiel and Meier 2004:116, Thiel and Mayer 2009:91), namely the control of key knowledge by a limited number of VSC-members.

In conclusion, veto potential against the integration of refugees within formal communication channels of VSCs seems limited. Nevertheless, these channels are suboptimal, because decisions are made mostly through information oligarchies $^{10}$, and posts that explicitly deal with integration have rarely or only informally been introduced. However, all analysed VSCs created these offers in spite of this. These findings already suggest that the implementation of sport offers for refugees largely depends on individuals, namely human resources, which will be further discussed in the next section.

\section{Human Resources}

The implementation of organisational decisions hinges on those active in the organisation. As we will argue in the following section, how or whether sport offers for refugees are realised greatly depends on the views of those club members voluntarily engaged within the organisations. Thiel and Mayer (2009:92) observed that in sport clubs, the best proof of a candidate's qualification for an honorary post is a longstanding membership and a club career as an athlete or dedicated volunteer. The consequence of this practice is a rather limiting and socially closed (Baur and Braun 2000) recruiting pool of volunteers in VSCs.

The individuals acting in the VSCs seem to be the driving force behind implementing offers for refugees. Indeed, the interview material shows that in most cases, the decision to make sport offers available to refugees can be attributed to a single person or to a small group of people:

CP: This was all run through me, I thought that that's important. I can do this within my job and I am the contact and all this stayed at my position. I think it's important that there is a central contact and it's not divided onto 2, 3, 4 shoulders. Of course, one is always in contact with one's cooperation partners, one's paid workers whoever is on-site. But everything was directly run through me. I wrote the application and took the project coordination, -planning, -implementation, etc. (OtS-17: Lines 29-30)

As mentioned, VSCs are member-based organisations which usually do not allow external individuals to make relevant club decisions and are normally considered closed to change and innovation (Thiel and Meier 2004). This research suggests that the individuals who implemented sport offers for refugees were already active in the sport club and disposed to social engagement beyond the

${ }^{10}$ Information oligarchies endanger the power of arguments as well as the possibility of co-determination within other decision-making entities, like the general assembly. 
expectation implied by their positions. Apparently, the arrival of an exceptionally high number of refugees was a stimulus, which led to them to act.

Research about sport participation of migrants has repeatedly shown that specific population groups can be successfully included in sport clubs by appointing individuals who are particularly sensitive to the needs of refugees and qualified to deal with the topic of integration (Seiberth et al. 2013:187). Furthermore, appointing people with such characteristics and a refugee background would create ideal conditions for implementing integration policies and promoting diversity within the clubs. The interviews show that, on the one hand, VSCs were aware of these concepts, but on the other hand, refugees were only rarely involved in the organization of activities. Reasons for this can be manifold, but most interviewees refer to the refugees' prioritisation of other everyday issues over sport and sport club engagement and to their uncertain and unstable living conditions.

Interviewer (I): Can you (imagine) employing refugees as volunteers? CP2: Would be great, of course!

CP1: Unfortunately, this didn't work out, we wanted this through the disabled sports federation, we were asked if we would take them. But this didn't happen because they didn't know where they were anymore, either they had been moved to another accommodation or something like this. And the contacts broke. We would like to do this through the Regional Sport Confederation, there are people with migration background, who are doing a year of voluntary service, there we have Carlos from Brazil and one from Holland. They looked for migrant themselves and didn't find many, this is probably due to the way of making contact. Then there are language barriers, so nobody can express what they originally intend to. Moreover, they don't know certain expressions at all. Bundesfreiwilligendienst (Federal Voluntary Service), how should they know what this means. (RWoSC-7: Lines 127-129)

While these arguments are consistent with recent research findings (Caperchione et al. 2009, O'Driscoll et al. 2014), part of the material suggests that low civic engagement rates among refugees in (self-)organised sport may also be caused by mechanisms of social closure within VSCs. Although the interviews show a low awareness of these mechanisms, Thiel and Mayer (2009) suggest that voluntary engagement in VSCs is not easily accessible. In order to further explore this issue, we refer to the exceptional example of cricket offers. Even though this sport is rather unpopular and unknown in Germany, four cricket sport offers were implemented and organised by (mostly previously, in some cases also newly arrived) refugees themselves and supported by other, non-refugee members within the VSCs. This finding suggests that a discrepancy between the know-how of non-refugee club-members and the wishes and interests of 
refugees can lead to a faster transfer of responsibilities to refugees. VSCs, which successfully integrated refugees in their voluntary work, also acknowledge this strategy as relevant for the successful implementation of these sport offers. These results thus underscore how the individuals behind VSCs are the most powerful engines for the creation of sport offers for refugees.

The "long summer of migration" was not only a unique situation on a societal level. It also created a unique situation for research about organisational behaviour and change. It has given us the chance to show how members of sport clubs can successfully initiate organisational change. However, the inclusion of refugees into VSCs' staff seems to be a seldom occurrence, despite the potential benefits for more effectively integrating refugees.

\section{Organisational Culture}

Another influential aspect for the integrative capacity of a VSC is its organisational culture, namely those decision premises that are not explicitly defined. Even though sport is often attributed with integrative potential, sport sociologists have stressed that organisational cultures can constitute conditions for intercultural openness as well as for social closure (Seiberth 2012, Soeffner and Zifonun 2008).

Our data suggests that external actors may influence organisational culture in favour of or at the expense of the integration of refugees in VSCs. Indeed, refugees are subjected to stereotyping and discrimination both in public perception (Zick, Pettigrew and Wagner 2008) and in media portrayals (Georgiou and Zaborowski 2017). They are often seen as outsiders who are somehow different from Europeans and this process of boundary-making can either result in positive (as vulnerable outsiders) or negative (as dangerous outsiders) connotations (Georgiou and Zaborowski 2017). The arrival of refugees in Germany triggered waves of solidarity (the so-called Willkommenskultur embodied by the motto "Refugees Welcome") and hostility (for example after the widespread sexual assaults on women during the New Year's Eve of 2015/16 in Cologne). ${ }^{11}$ These waves are also identifiable as relevant external positive or negative irritations for sport clubs:

$\mathrm{CP}$ : Right at the beginning, when the first refugees arrived, all this was new and interesting for everybody, and, "Oh, let's have a look at that!" Then all people became involved, then it was claimed that the people need clothes, then clothes were donated. That's how first contacts with the Red Cross were made who were in charge there. And then we said at some point "Look people, we have a sport club here, can we support you in some way and do something with the

\footnotetext{
${ }^{11}$ Georgiou \& Zaborowski (2017) note that the narratives of the coverage on refugees generally changed across Europe during this period: "The sympathetic and empathetic response of a large proportion of the European press in the summer and especially early autumn of 2015 was gradually replaced by suspicion and, in some cases, hostility towards refugees and migrants."
} 
children?" That's how it went. (OtS-1: Line 14) $\mathrm{CP} 1:[\ldots]$... we have been called traitor of the nation. On Facebook one has to read things like that. At the confiscation of the gym there was the NPD, pictures had been taken, I was in one of them, this was on the page and then it was stated that the dropouts had been due to our asylum politics in the chair. One turns around more often, not that there is somebody standing there.

CP2: [...] the NPD was marching up, and the police had to clear the path for us. We had been accused, because we didn't resist. We could shelter some material like bicycles at a member's place. We made a call and the answer was, "We would rather die than give you a square meter of space." What's going on is really mean. (RWoSC-7: Lines 36-37) ${ }^{12}$

Apart from these external irritations, we can furthermore identify internal irritations. Club members also have certain stereotypes and social attributions about refugees and integration. These attitudes are expressed in the organisational culture of the sport club and may thus either lead to rather discriminatory or to rather welcoming mechanisms, respectively.

When taking a closer look at organisational cultures that contribute to exclusion, two relevant mechanisms can be identified. Firstly, there is a strong tendency for boundary making. Refugees are often perceived as being different. Certain ascriptions, which portray them as less educated or as representatives of traditional gender roles are quite common and can lead to symbolic boundaries which - once established within the culture of an organisation - can lead to discriminatory practise (Krumer-Nevo and Sidi 2012, Lamont and Molnár 2002).

CP: The people from the Mediterranean are naturally a bit more emotional and you can tell the difference. That means that they are very clumsy and uncoordinated regarding sports. There you can see that they were never involved in a sport club. Regarding their character, they are not aggressive but thin-skinned. You always have the feeling that there can be trouble between the Afghan boys. But not within the group. That's a phenomenon I recognized here. I always thought that it would be an illusion. Meaning that if you haven't developed certain competences at the top, you go back to primitive measures. Then you think like in the animal world. These are the Afghans, the Arabs and the dark-skinned people. You have to take care of this now. This was not the case at the beginning. This is also due to the fact that everyone was euphoric at the beginning. And now there are problem at we have to keep an eye on them. One has to admit that. (RWoSC-5: Line 41)

Secondly, our data suggest that there is strong resistance and sometimes even fear of change or reorientation within VSCs (Seiberth et al. 2013:192). As a

${ }^{12}$ Between 2015 and 2016, 3,400 sports clubs in Germany lost part of their sport facilities because they were used as refugee accommodations. (Breuer et al. 2017) 
consequence, clubs which have never dealt with integration before were likely to have more problems in realizing sport offers for refugees compared to those clubs with experience in diversity management. However, defence mechanisms were also identifiable in sport clubs with much integration experience. These mechanisms generally concern diffuse fears of losing club traditions. However, in most cases, the integration of refugees created contrasts that revived the ideology and tradition of the club.

$\mathrm{CP}$ : And the club did change a little, because now the older people, too, for example bowling is mainly done by the older group, are very cautious and conservative against the refugees, because there is a certain fear. They walk up to them, they are excited, when they meet each other in the city, because the refugees are very well-educated. For them, older people are persons to respect and they get very excited and have fun and I found out that they even like to do [bowling] with them. They welcomed them to their community, they even celebrate Christmas parties together, there are friendships growing. (OtS-15: Line 87)

In conclusion, the club culture is a historically developed ensemble of informal rules, which may also involve the topic of integration. An already integration-orientated club culture or the ability to break with the traditional non-integrative self-concept influences the capacity of VSCs to create offers for refugees. While the modification of a club's culture is normally a slow process, the integration of refugees has the power to prompt rapid change in sport clubs. Our data cannot prove or measure the influence of public opinion, politics, and mass media on VSCs' integration policies. However, the interviewees report that in their opinion, these external conditions have in some cases influenced the culture of their VSCs. In turn, the presence of refugees in sport clubs can exemplify positive openness to diversity and the personification of otherness (Seiberth and Thiel 2010), namely of everything that is not commensurable with the culture of the club.

\section{Discussion}

The results presented above demonstrate that formal and informal structures of VSCs can promote or hinder the implementation of sport offers for refugees. From a systems theoretical perspective, four types of decision premises for the implementation of sport offers for refugees were analysed and discussed: decision programmes, communication channels, human resources and organisation culture. 
Table 1: Conditions Promoting and Hindering VSCs' Decision Premises

\begin{tabular}{|c|c|c|}
\hline $\begin{array}{c}\text { Decision } \\
\text { Premise }\end{array}$ & Promoting & Hindering \\
\hline $\begin{array}{c}\text { Decision } \\
\text { Programmes }\end{array}$ & $\begin{array}{c}\text { Existence of integration as a goal in pur- } \\
\text { pose programmes and of previous inte- } \\
\text { grative sport offers; guidelines to lead the } \\
\text { implementation and evaluation of integra- } \\
\text { tive programmes }\end{array}$ & $\begin{array}{c}\text { Absence of integration as a goal } \\
\text { in purpose programmes and of } \\
\text { previous integrative sport offers }\end{array}$ \\
\hline $\begin{array}{c}\text { Communication } \\
\text { Channels }\end{array}$ & $\begin{array}{c}\text { Low veto potential through clubs' commu- } \\
\text { nicative structures; information oligarchies } \\
\text { pro integration }\end{array}$ & $\begin{array}{c}\text { Non-existent or only formally } \\
\text { existing posts for integration }\end{array}$ \\
\hline $\begin{array}{c}\text { Human } \\
\text { Resources }\end{array}$ & $\begin{array}{c}\text { High engagement for refugees of persons } \\
\text { working in the VSCs }\end{array}$ & $\begin{array}{c}\text { Exclusion of refugees in club } \\
\text { personnel }\end{array}$ \\
\hline $\begin{array}{c}\text { Organisation } \\
\text { Culture }\end{array}$ & $\begin{array}{c}\text { Integrative culture; changing capacity; pos- } \\
\text { itive external influence; welcoming culture }\end{array}$ & $\begin{array}{c}\text { Non-integrative culture; resist- } \\
\text { ance to change; negative external } \\
\text { influence; discrimination }\end{array}$ \\
\hline
\end{tabular}

It can be observed that these conditions embedded in the decision premises are interrelated and path-dependent. Previous experiences with integration serve as a good foundation for further similar practises in the interviewed clubs. However, for some VSCs with no integration history, the recent migration flow was the trigger to initiate diversity policies. This is somehow surprising, given the theoretical assumption that VSCs are autopoietic systems, which are hardly irritable through external impulses and resistant to innovation (Thiel and Meier 2004). Yet our analyses show that clubs reacted to the so-called "refugee crisis" and were able to mobilise an enormous voluntary commitment.

The evaluated sport offers are carried out with limited economic resources and are perceived as well functioning by the organisers, who intend to continue the activities in most cases. They also perceive the sport offers as helpful for the refugees and as facilitating their integration process. ${ }^{13}$ In some cases, sport clubs benefit from the new members and their individual abilities and interests. The social commitment with refugees seems to release energies within sport clubs and is an opportunity to attract new members, especially for those VSCs with declining membership rates. Most importantly, it is clear that VSCs do not only follow the narrow sportive logic "victory/defeat", but also carry out a very relevant social function by implementing health, education, and social programmes for refugees. For example, volunteers of VSCs who carried out the sport offers had to deal with the lack of basic living conditions of refugee camps (Lewek and Naber 2017) and carried out (humanitarian) activities which included the transportation to and from the sport facilities, the donation of (sport) clothes, childcare and (psychological) counselling.

\footnotetext{
${ }^{13}$ Nevertheless, these statements should be confirmed by including the point of view of the refugees on this topic.
} 
Nevertheless, VSCs also report that they are overwhelmed with these functions and complain about a lack of support. In many cases, the work with refugees is perceived as exhausting and overwhelming. The most part of the overall responsibility is carried on the shoulders of few human resources, who are mainly volunteers who lack the necessary time, energy, experience, qualification and training. Moreover, the interviews reveal deficits in structural and economical resources to realize the offers. The sustainability of the offers is in part dependent on additional external support, and the interviewees perceive a decreasing willingness among the population to help and donate. This situation causes a permanent feeling of urgency and overwork.

Recommendations aiming to support inclusive sport offer for people with a migration background have been elaborately formulated by Kleindienst-Cachay et al. (2007:261, 2012:121-24). They include: selection of a specific target group, promotion of sport at an early age, combination of ethnic and mixed offers, cooperation with external actors and offers, choice of selected sport disciplines, support of best practices, advanced training of VSCs' staff, long term sustainability of the offers, and political support. With a few modifications, these recommendations can be applied to the refugee situation. However, human resources seem to play a central role regarding the implementation of sport offers for refugees within all the decision premises considered in the article. In our interviews, these human resources seem to be the most meaningful and crucial predictor for the creation and a key to ensure the existence and sustainability of these offers. In order to "fuel" the commitment of these people, their initiative needs to be safeguarded, fostered, and facilitated. From a utopian perspective, this should be done by offering economic and structural resources, training courses, and the support of professionals (for example psychologists, dieticians, social workers) to VSCs. While the realisation of these measures is highly improbable, they would definitely be justified, under the circumstances.

This paper concludes with a reflexion on its limitations and desiderata. Under theoretical aspects, research on forced migration has been criticised for its mostly low-range theoretical explanations (Castles 2003, Portes 1997). This article used a long-range theory instead, which could easily be expanded and linked to further local, national, and global phenomena. Nevertheless, the systems theoretical concepts for examining organisations were suboptimal to grasp further conditions, like the economic and structural resources of VSCs. The use of a middle-range theory, like the concept of organisational capacity (Hall, Andrukow, Barr et al. 2003), could complement this deficit in our analyses. Under methodological aspects, first empirical-based statements could be quickly generated in Germany through small scale and cross-sectional studies, like those discussed in this article. The first step toward creating a more inclusive and ambitious research programme is to aggregate the data of these "micro studies" and create research networks, as demonstrated in this article. Ideally, the task of conducting independent and neutral observations of different social phenomena concerning "sport and refugees" would be carried out further through large- 
scale, multi-methodological and longitudinal research projects. Among other relevant questions, such studies should focus on the perspective of refugees and the long-term organisational development of different VSCs (by including also migrant VSCs). Only in this way can empirical findings be confirmed and recommendations for integrating refugees in and through sport derived.

\section{REFERENCES}

Bahlke, Steffen and Christa Kleindienst-Cachay. 2017. „Migrantinnen und Migranten im organisierten Sport.” Pp. 139-51 in Sport \& Gender - (inter)nationale sportsoziologische Geschlechterforschung: Theoretische Ansätze, Praktiken und Perspektiven, edited by G. Sobiech and S. Günter. Wiesbaden: Springer.

Baur, Jürgen and Sebastian Braun. 2000. Freiwilliges Engagement und Partizipation in ostdeutschen Sportvereinen: eine empirische Analyse zum Institutionentransfer. Köln: Strauß.

Bette, Karl-Heinrich. 1999. Systemtheorie und Sport. Frankfurt am Main: Suhrkamp.

Binder, Susanne and Jelena Tošić. 2005. „Refugees as a Particular Form of Transnational Migrations and Social Transformations: Socioanthropological and Gender Aspects.” Current Sociology 53(4):60724. doi: 10.1177/0011392105052717.

Block, Karen and Lisa Gibbs. 2017. „Promoting Social Inclusion Through Sport for Refugee-Background Youth in Australia: Analysing Different Participation Models.” Social Inclusion 5(2):91-100. doi: 10.17645/si.v5i2.903.

Braun, Virginia and Victoria Clarke. 2006. „Using Thematic Analysis in Psychology.” Qualitative Research in Psychology 3(2):77-101. doi: 10.1191/1478088706qp063oa.

Braun, Virginia and Victoria Clarke. 2012. „Thematic Analysis.” Pp. 57-71 in APA Handbook of Research Methods in Psychology, edited by H. Cooper and American Psychological Association. Washington, DC: Magination.

Breuer, Christoph, Svenja Feiler and Tobias Nowy. 2017. „Sportvereine, Sportbünde und Flüchtlinge.” Pp. 47-100 in Sportentwicklungsbericht 2015/2016. Analyse zur Situation der Sportvereine in Deutschland, edited by C. Breuer. Köln: Strauß.

Burrmann, Ulrike, A. Rübner, Sebastian Braun, Tina Nobis, R. Langner, Michael Mutz, A. Marquez-Lopez and M. Rickert. 2014. „Ziele, Konzepte und Wirkungen sportbezogener Integrationsarbeit aus Sicht der Funktionsträger/-innen des DOSB-Programms „Integration durch Sport“.” (http://www.integration-durch-sport.de/fileadmin/fm-dosb/arbeitsfelder/ids/files/downloads_pdf/downloads_2014/ Evaluation_Programm_Integration_durch_Sport_2013.pdf).

Burrmann, Ulrike, Michael Mutz and Ursula Zender, eds. 2015. Jugend, Migration und Sport: Kulturelle Unterschiede und die Sozialisation zum Vereinssport. Wiesbaden: Springer.

Caperchione, Cristina M., Gregory S. Kolt and W. Kerry Mummery. 2009. „Physical Activity in Culturally and Linguistically Diverse Migrant Groups to Western Society.” Sports Medicine 39(3):167-77. doi: 10.2165/00007256-200939030-00001.

Castles, Stephen. 2003. „Towards a Sociology of Forced Migration and Social Transformation.” Sociology 37(1):13-34. doi: 10.1177/0038038503037001384.

Clayton, Jonathan. 2015, „Chief Issues Key Guidelines for Dealing with Europe’s Refugee Crisis”: UNHCR. (http://www.unhcr.org/55e9793b6.html). 
DOSB, ed. 2014. Expertise. „Diversität, Inklusion, Integration und Interkulturalität - Leitbegriffe der Politik, sportwissenschaftliche Diskurse und Empfehlung für den DOSB und die dsj“. Frankfurt am Main: INKA Medialine. (http://www.integration-durch-sport.de/fileadmin/fm-dosb/arbeitsfelder/ids/ images/2014/downloads/Expertise_Diversitaet_Inklusion_Integration_Interkulturalitaet.pdf).

Elling, Agnes, Annelies Knoppers and Paul De Knop. 2001. „The Social Integrative Meaning of Sport:

A Critical and Comparative Analysis of Policy and Practice in the Netherlands." Sociology of Sport Journal 18:414 - 34. doi: 10.1123/ssj.18.4.414.

European Commission 2007. White Paper on Sport. (9279065521). Brussels: Office for Official Publications of the European Communities.

Georgiou, Myria and Rafal Zaborowski. 2017. Media Coverage of the "Refugee Crisis": A Cross-European Perspective. Strasbourg: Council of Europe.

German Federal Government. 2007. Der Nationaler Integrationsplan. Berlin: German Federal Government. Ha, Jae-Pil and Alexis Lyras. 2013. „Sport for Refugee Youth in a New Society: The Role of Acculturation in Sport for Development and Peace Programming." South African Journal for Research in Sport, Physical Education and Recreation 35(2):121-40.

Hall, Michael H, Alison Andrukow, Cathy Barr, Kathy Brock, Margaret De Wit, Don Embuldeniya, Louis Jolin, David Lasby, Benoit Levesque and Eli Malinsky. 2003. The Capacity to Serve: A Qualitative Study of the Challenges Facing Canada's Nonprofit and Voluntary Organizations. Toronto: Canadian Centre for Philanthropy.

Hartley, Lisa, Caroline Fleay and Marian E Tye. 2017. „Exploring Physical Activity Engagement and Barriers for Asylum Seekers in Australia Coping with Prolonged Uncertainty and no Right to Work." Health \& Social Care in the Community 25(3):1190-98. doi: 10.1111/hsc.12419.

Heinemann, Klaus and Heinz-Dieter Horch. 1988. „Strukturbesonderheiten des Sportvereins.” Pp. 10822 in Sport im Verein und im Verband: Historsiche, politische und soziologische Aspekte, edited by $\mathrm{H}$. Digel. Schorndorf: Hofmann.

Horch, Heinz Dieter 1989. „Sociological Research on Sports Organizations in the Federal Republic of Germany: An Overview." International Review for the Sociology of Sport 24(3):201-16. doi: $10.1177 / 101269028902400302$.

Kleindienst-Cachay, Christa. 2007. Mädchen und Frauen mit Migrationshintergrund im organisierten Sport. Ergebnisse zur Sportsozialisation-Analyse ausgewählter Maßßnahmen zur Integration im Sport. Hohengeren: Schneider.

Kleindienst-Cachay, Christa, Klaus Cachay, Steffen Bahlke and Hilke Teubert. 2012. Inklusion und Integration: eine empirische Studie zur Integration von Migrantinnen und Migranten im organisierten Sport. Schorndorf: Hofmann.

Krumer-Nevo, Michal and Mirit Sidi. 2012. „Writing Against Othering.” Qualitative Inquiry 18(4):299309. doi: 10.1177/1077800411433546.

Lamont, Michèle and Virág Molnár. 2002. „The Study of Boundaries in the Social Sciences.” Annual Review of Sociology 28(1):167-95. doi: 10.1 146/annurev.soc.28.110601.141107.

Lewek, Mirjam and Adam Naber. 2017. „Kindheit im Wartezustand - Studie zur Situation von Kindern und Jugendlichen in Flüchtlingsunterkünften in Deutschland." (https://www.unicef.de/informieren/ aktuelles/presse/2017/studie-fluechtlingskinder-in-deutschland/137440).

Lidor, Ronnie, Karl-Heinz Schneider and Katrin Koenen, eds. 2011. Sport as a Mediator between Cultures. Israel: ICSSPE.

Luhmann, Niklas. 2003. Social Systems. Translated by J. J. Bednarz and D. Baecker. Stanford: Stanford 
University Press.

Luhmann, Niklas. 2006. Organisation und Entscheidung. Wiesbaden: VS.

Meier, Heike, Lars Riedl and Marc Kukuk. 2016. „Soziologische Herausforderungen durch Migration, Inklusion und Integration im Sport." Pp. 1-15 in Migration, Inklusion und Integration : soziologische Beobachtungen des Sports, edited by H. Meier, L. Riedl and M. Kukuk. Baltmannsweiler: Schneider.

Mutz, Michael. 2012. Sport als Sprungbrett in die Gesellschaft. Sportengagements von Jugendlichen mit Migrationshintergrund und ihre Wirkung. Weinheim: Beltz Juventa.

Nobis, Tina. 2013. „Multikulturelle Zivilgesellschaft? Sportverbände und-vereine als Akteure der Integrationsarbeit." Pp. 46-69 in Der Deutsche Olympische Sportbund in der Zivilgesellschaft, edited by S. Braun. Wiesbaden: Springer.

O’Driscoll, Téa, Lauren Kate Banting, Erika Borkoles, Rochelle Eime and Remco Polman. 2014. „A Systematic Literature Review of Sport and Physical Activity Participation in Culturally and Linguistically Diverse (CALD) Migrant Populations." Journal of Immigrant and Minority Health 16:515-30. doi: 0.1007/s 10903-013-9857-x.

Portes, Alejandro. 1997. „Immigration Theory for a New Century: Some Problems and Opportunities.” International Migration Review 31(4):799-825.

Rittner, Volker and Christoph Breuer. 2004. Gemeinwohlorientierung und soziale Bedeutung des Sports. Köln: Strauß.

Schimank, Uwe. 1988. „Die Entwicklung des Sports zum gesellschaftlichen Teilsystem.” Pp. 181-232 in Differenzierung und Verselbständigung: Zur Entwicklung gesellschaftlicher Teilsysteme, edited by R. Mayntz. Frankfurt am Main: Campus.

Schimank, Uwe. 2002. „Der Vereinssport in der Organisationsgesellschaft: organisationssoziologische Perspektiven auf ein spannungsreiches Verhältnis." (http://www.zhb.tu-dortmund.de/wilkesmann/ fussball/_publi/OLDENBURG.pdf).

Seiberth, Klaus and Ansgar Thiel. 2010. „Cultural Diversity and Otherness in Sport-Prospect and Limits of Integration." Pp. 189-203 in Migration, Integration, and Health: The Danube Region, edited by H. C. Traue, R. Johler and J. J. Gavrilovic. Lengerich: Pabst Science.

Seiberth, Klaus. 2012. Fremdheit im Sport: ein theoretischer Entwurf; Erscheinungsformen, Erklärungsmodelle und pädagogische Implikationen. Hofmann: Schorndorf.

Seiberth, Klaus, Yvonne Weigelt-Schlesinger and Torsten Schlesinger. 2013. „Wie integrationsfähig sind Sportvereine?-Eine Analyse organisationaler Integrationsbarrieren am Beispiel von Mädchen und Frauen mit Migrationshintergrund." Sport und Gesellschaft 10(2):174-98.

Soeffner, Hans-Georg and Dariuš Zifonun. 2008. „Fußballwelten: Die Ordnungen interethnischer Beziehungen." Pp. 133-61 in Mittendrin im Abseits. Ethnische Gruppenbeziehungen im lokalen Kontext, edited by S. Neckel and H.-G. Soeffner. Wiesbaden: VS.

Stichweh, Rudolf. 1990. „Sport-Ausdifferenzierung, Funktion, Code.” Sportwissenschaft 20(4):373-89.

Thiel, Ansgar. 1997. Steuerung im organisierten Sport: Ansätze und Perspektiven. Stuttgart: Naglschmid.

Thiel, Ansgar and Heiko Meier. 2004. „Überleben durch Abwehr-Zur Lernfähigkeit des Sportvereins.” Sport und Gesellschaft 1(2):103-24.

Thiel, Ansgar and Heiko Meier. 2008. „Wie innovationsfähig ist der Sportverein? Eine Analyse am Beispiel der Einrichtung hauptberuflicher Mitarbeiterstellen." Pp. 129-46 in Sport in Deutschland. Bestandsaufnahmen und Perspektiven, edited by M. K. W. Schweer. Frankfurt am Main: Lang.

Thiel, Ansgar and Jochen Mayer. 2009. „Characteristics of voluntary sports clubs manage- 
ment: A sociological perspective." European Sport Management Quarterly 9(1):81-98. doi: $10.1080 / 16184740802461744$.

UNHCR. 2010. Convention and Protocol Relating to the Status of Refugees. Geneva: UNHCR.

Zick, Andreas, Thomas F. Pettigrew and Ulrich Wagner. 2008. „Ethnic Prejudice and Discrimination in Europe." Journal of Social Issues 64(2):233-51. 